\title{
Status of black-legged kittiwakes (Rissa tridactyla), common guillemots (Uria aalge) and Brünnich's guillemots (U. Iomvia) in Murman, north-west Russia, and Varanger, north-east Norway
}

\author{
Yuri V. Krasnov ${ }^{1}$, Robert T. Barrett ${ }^{2} \&$ Natalie G. Nikolaeva ${ }^{3}$ \\ 1 Murmansk Marine Biological Institute, Vladimirskaya st. 17, RU 183010 Murmansk, Russia \\ 2 Tromsø University Museum, Zoology Department, NO-9037 Tromsø, Norway \\ 3 Russian Bird Conservation Union, Entuziastov Shosse, 60 bld. 1, RU 111123 Moscow, Russia
}

\section{Keywords}

Kittiwakei; guillemot; population status; Barents Sea.

\section{Correspondence}

Robert T. Barrett, Tromsø University Museum, Zoology Department, NO-9037 Tromsø, Norway. E-mail: robb@tmu.uit.no

doi:10.1111/j.1751-8369.2007.00015.x

\begin{abstract}
Recent published estimates of the numbers of seabirds breeding along the coast of Murman have been partly based on data collected in the 1960s. Counts made in some of the largest colonies in 1999-2005 show that the present populations of black-legged kittiwakes (Rissa tridactyla), common guillemots (Uria aalge) and Brünnich's guillemot (U. lomvia) in Murman are approximately 110000 pairs, 10 000-12 000 pairs and 2000-3000 pairs, respectively. In Varanger the numbers are ca. 32000 pairs, 6000-7000 pairs and 400-500 pairs, respectively. Although there has been a large decline in black-legged kittiwake numbers in the Varanger region since 1980, there is no evidence of a similar decline in Murman at least until 1999. With the exception of one colony in Murman, numbers of common guillemots breeding throughout the region seem to have recovered after suffering a huge decline in 1986/87.
\end{abstract}

The Barents Sea is one of the most important seabird areas in the world, with more than seven million pairs of about 40 species breeding in several hundred colonies on Svalbard, Frans Josef Land, Novaya Zemlya and along the mainland coasts of north-west Russia and north-east Norway (Anker-Nilssen et al. 2000).

In recent years concern has been raised about the effects that climate change may have on Arctic and subArctic species, and emphasis has been put on the need for sound documentation of animal population dynamics. For example, recent studies have demonstrated climatedriven changes at low and mid-trophic levels, and how these have affected seabirds (Durant et al. 2003, 2006; Frederiksen et al. 2006). Furthermore, the huge fluctuations in forage fish stocks (capelin [Mallotus villosus] and herring [Clupea harengus]) the development and transport of petroleum resources in the Barents Sea off the Murman and Finnmark coast, and the huge impact these can have on seabirds has resulted in the need of new appraisals of the status and population trends of seabirds breeding in the area (Quillfeldt \& Dommasnes 2005a,b; Iversen et al. 2006). Although extensive documentation was recently published in a status report for the Barents Sea (Anker-Nilssen et al. 2000), totals for some of the Russian colonies dated as far back as the early 1960s (Gerasimova 1962). Here we present up-to-date estimates of the populations of three of the common species, the blacklegged kittiwake (hereafter kittiwake [Rissa tridactyla]), common guillemot (Uria aalge) and Brünnich's guillemot (U. lomvia) on all colonies in the Varanger area of East Finnmark, and on the five largest colonies on the coast of Murman (which contained $>95 \%$ of all guillemots and $>80 \%$ of all black-legged kittiwakes breeding in the region; Golovkin 1984).

\section{Material and methods}

Of the five largest colonies of kittiwakes and guillemots along the Murman coast (Fig. 1), two (Kharlov and Kuvshin) were surveyed in 1995-1999 and three (Cape Gorodetskiy, Cape Krutik and Dvorovaya Bay) were surveyed in one or more years between 2000 and 2005. Colonies in Sør-Varanger, Store Ekkerøy and Hornøya (Fig. 1) were surveyed in 2006, and two smaller colonies in the inner part of the Varanger Fjord were surveyed in 1999.

All surveys were made during the incubation and/or hatching periods. In Russia, single counts were made 


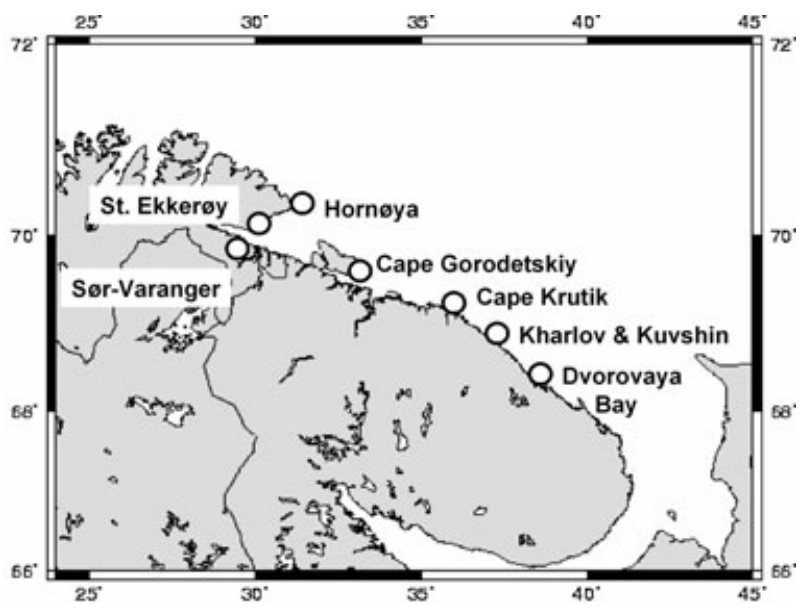

Fig. 1 Map showing the main seabird colonies in Varanger and along the Murman coast. (Map outline from http://www.aquarius.ifm-geomar.de/ make_map.html.)

from the land either directly or, in the densest parts of the colonies, from photographs. In Varanger, nearly all kittiwake counts were made directly from the deck of RV Johan Ruud (110 ft) or, in the case of the largest colonies, from mosaics of digital colour photographs taken from the same platform.

At Cape Gorodetskiy, on the east coast of the Ribachiy Peninsula, a total count was made in 2000. Photographs were taken of the densest parts of the colony, and 13 kittiwake and five guillemot control plots were used as the basis for the next count in 2002. At Cape Krutik, near Dalniye Zelentsi, annual counts of kittiwakes and guillemots were made in 2000-2003 and 2004. At Dvorovaya Bay, counts were made in 2003 and 2005. Total counts were made from land in 2003; in 2005 total counts of guillemots were also made from land, whereas numbers of kittiwakes were determined from counts in control plots. At Kharlov and Kuvshin, population counts were made in 1999 as part of the then ongoing monitoring of the colony (Krasnov et al. 1995). Kittiwake clutch sizes (numbers of eggs in samples of nests containing eggs) were recorded in each colony at each visit.

In Norway, all colonies in Sør-Varanger and at Store Ekkerøy were visited once on 8-11 June 2006, whereas Hornøya has been visited over longer periods almost every year since 1980 for detailed monitoring (Barrett 2001; Lorentsen 2006). A total count of kittiwakes at Hornøya was made in June 2006, based on a combination of direct counts on some of the cliffs and counts from photographs of the remainder. Estimates of the total guillemot population at Hornøya were based on single total counts made during the late incubation period in 1996 and 2001, and on detailed monitoring
Table 1 Numbers of black-legged kittiwake (Rissa tridactyla) (apparently occupied nests) counted in colonies along the Murman coast in 19992005.

\begin{tabular}{lcc}
\hline Colony & Number & Year \\
\hline Cape Gorodetskiy & 50175 & 2000 \\
Cape Krutik & $47666^{\mathrm{a}}$ & 2002 \\
& 4286 & 2000 \\
& 3420 & 2002 \\
& 3547 & 2003 \\
Kharlov & 3549 & 2004 \\
Dvorovaya Bay & 23000 & 1999 \\
& 32330 & 2003 \\
& $37628^{\mathrm{a}}$ & 2005 \\
\hline
\end{tabular}

${ }^{a}$ Totals based on counts in control plots.

counts since 1988 (Barrett 2001). Counting units were apparently occupied nests for kittiwakes and individuals for guillemots.

\section{Results}

\section{Kittiwake}

About 50000 pairs of kittiwakes were counted at Cape Gorodetskiy in 2000, making it the largest colony in Murman (Table 1). Based on counts of 4425 nests in 13 plots established in 2000 (and which made up ca. 3\% of the total population), the population in 2002 was estimated to be 48000 pairs. At Dvorovaya Bay, a total count of 32330 pairs was made in 2003. Based on plots containing 946 nests (or 9\% of the population) in 2003 and 1101 nests in 2005, the 2005 total was estimated to be ca. 37000 pairs, making Dvorovaya Bay the second largest colony in Murman. A further 3500 pairs were counted on Cape Krutik and, in 1999, 23000 pairs were counted on Kharlov, giving a total of ca. 110000 pairs in the four colonies. Assuming that they constitute $80 \%$ of the total population, this gives a figure of ca. 140000 pairs for Murman.

Around the Varanger Fjord, about 3500 pairs of kittiwakes were counted in Sør-Varanger, 15500 pairs on Store Ekkerøy and 11 500-12 000 pairs on Hornøya in 2006. With a near halving of numbers on Hornøya since the early 1980s (Lorentsen 2006; Barrett et al. in press), the population on the neighbouring island Reinøya (2000 pairs in 1983; Furness \& Barrett 1985) was estimated to be ca. 1000 pairs in 2006. A further 900 pairs were counted on two colonies in the inner part of Varanger Fjord in 1999 (Fugleberget, 700 pairs; Skjaaholmen, 200 pairs). This gives a total of about 31 000-32000 pairs breeding between the Norwegian-Russian border and Hornøya.

Kittiwake clutch sizes are given in Table 2 . 
Table 2 Mean clutch sizes (excluding empty nests) of black-legged kittiwakes (Rissa tridactyla) in colonies in Varanger and along the Murman coast in 1995-2005.

\begin{tabular}{|c|c|c|c|c|c|c|c|c|c|c|c|c|c|c|c|}
\hline \multirow[b]{2}{*}{ Colony } & \multicolumn{3}{|c|}{ Hornøya } & \multicolumn{3}{|c|}{ Cape Gorodetskiy } & \multicolumn{3}{|c|}{ Cape Krutik } & \multicolumn{3}{|c|}{ Kharlov } & \multicolumn{3}{|c|}{ Dvorovaya Bay } \\
\hline & Mean & SE & $N$ & Mean & SE & $N$ & Mean & SE & $N$ & Mean & SE & $N$ & Mean & SE & $N$ \\
\hline 1995 & 1.78 & 0.02 & 668 & - & - & - & - & - & - & 1.70 & 0.03 & 327 & - & - & - \\
\hline 1996 & 1.78 & 0.02 & 838 & - & - & - & - & - & - & 1.46 & 0.04 & 193 & - & - & - \\
\hline 1998 & 2.11 & 0.02 & 782 & - & - & - & - & - & - & 1.93 & 0.03 & 401 & - & - & - \\
\hline 2000 & 1.76 & 0.02 & 844 & 1.15 & 0.04 & 66 & 1.66 & 0.07 & 53 & - & - & - & - & - & - \\
\hline 2002 & 2.04 & 0.02 & 787 & 1.17 & 0.02 & 462 & 1.24 & 0.05 & 90 & - & - & - & - & - & - \\
\hline 2003 & 1.75 & 0.02 & 660 & - & - & - & 1.32 & 0.05 & 101 & - & - & - & 1.21 & 0.05 & 67 \\
\hline 2004 & 1.64 & 0.02 & 675 & - & - & - & 1.25 & 0.05 & 85 & - & - & - & 1.72 & 0.04 & 167 \\
\hline 2005 & 1.86 & 0.02 & 730 & - & - & - & - & - & - & - & - & - & - & - & - \\
\hline
\end{tabular}

$N$, number of nests with eggs; SE, standard error of mean.

Table 3 Numbers of common (Uria aalge) and Brünnich's guillemots (U. lomvia) (individuals) counted in colonies along the Murman coast in 1999-2005.

\begin{tabular}{lccc}
\hline Colony & U. aalge & U. lomvia & Year \\
\hline Cape Gorodetskiy & 2500 & $70-80$ & 2000 \\
& $2400^{a}$ & $70-80^{a}$ & 2002 \\
Cape Krutik & 105 & 35 & 2000 \\
& 75 & 90 & 2002 \\
Kharlov & 52 & 76 & 2003 \\
Kuvshin & 43 & 64 & 2004 \\
Dvorovaya Bay & 5800 & - & 1999 \\
& $7000-10000$ & 23 & 1999 \\
& 1063 & 17 & 2003 \\
\hline
\end{tabular}

${ }^{\mathrm{a}}$ Totals based on counts in control plots.

\section{Common guillemot}

In Murman, 2593 guillemots (1287 common guillemots, 40 Brünnich's guillemots and 1266 unidentified guillemots) were counted at Cape Gorodetskiy in 2000. Five monitoring plots were defined and contained 705 common guillemots and 25 Brünnich's guillemots (or $28 \%$ of the total number of guillemots). Based on repeat counts in these plots, the total population in 2002 was estimated to be 2487 individuals, of which 2400 were common guillemots (Table 3). At Cape Krutik the guillemot population was very fragmented and spread among the kittiwake nests, and the numbers of common guillemots varied between 50 and 100 individuals. At Dvorovaya the population was between 700 and 1000 individuals in 2003 and 2005, respectively. In 1999, 5800 individuals were counted at Kharlov and 7000-10 000 individuals were counted at Kuvshin. Cape Gorodetskiy, Kharlov, Kuvshin and Dvoroyava Bay are by far the four largest guillemot colonies in Murman, with a total breeding population of ca. 16 000-19000 individuals. Assuming that they make up $95 \%$ of the total population, this gives a

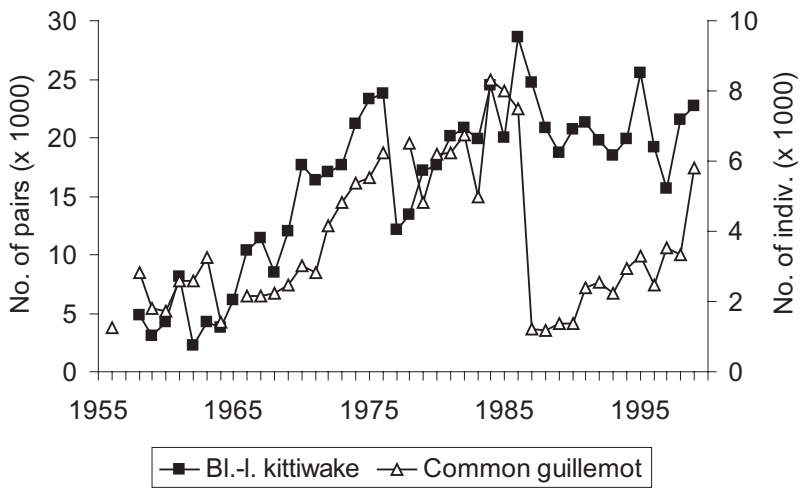

Fig. 2 Numbers of black-legged kittiwakes (Rissa tridactyla pairs; $\mathbf{\square}$ ) and common guillemots (Uria aalge individuals; $\triangle$ ) breeding on Kharlov, Murman, 1954-1999.

total figure of 16 500-20000 individuals or, assuming a conversion factor of 0.6 individuals/pair (Anker-Nilssen et al. 2000), 9900-12 000 pairs for Murman.

In Varanger, common guillemots were found only on Hornøya and Reinøya. In 1989, 1900 individuals were counted on Hornøya, ca. 4000 in 1996 and ca. 6400 in 2001 . Based on the known rate of population increase in the colony (Lorentsen 2006), the population in 2006 was estimated to be ca. 10000 individuals. Assuming the population on Reinøya is $10 \%$ of that on Hornøya (Furness $\&$ Barrett 1985), the total population for both islands in 2006 was estimated to be ca. 11000 individuals, or 6600 pairs.

\section{Brünnich's guillemot}

The coasts of Murman and Varanger are near the southern limit of the distribution of Brünnich's guillemot, and their numbers are therefore small. At Cape Gorodetskiy, the precise numbers are unknown but are thought to be in the order of 70-80 individuals. At Cape Krutik the 
population was 50-100 individuals, and at Dvorovaya Bay ca. 20 individuals were counted (Table 3). In 1999, 3000-5000 individuals were counted at Kuvshin, and 1639 individuals were counted at Kharlov. The colonies at Kuvshin and Kharlov constitute nearly the total Brünnich's guillemot population in Murman, giving a total of 4600-6600 individuals, or ca. 3000-4000 pairs.

At Hornøya, ca. 600 individuals were counted in 2001. Assuming that there were ca. 100 individuals on Reinøya (ca. 14\% of the Hornøya population; Furness \& Barrett 2005) and that there has been little change since (RTB, unpubl. data), the 2006 population on Hornøya and Reinøya was estimated to be on the order of 700-800 individuals, or 400-500 pairs.

\section{Discussion}

Prior to these surveys, the total kittiwake population along the Murman coast was estimated to be 66900 pairs in about 1980 (Golovkin, 1984; Anker-Nilssen et al. 2000). Apart from Cape Gorodetskiy, Cape Krutik, Kharlov and Dvoroyava Bay, earlier studies (e.g. Gerasimova 1962) documented 12 or 13 colonies with less than 5000 pairs in total. Although numbers have dropped by ca. $50 \%$ in two colonies monitored in north Norway since 1980 (Barrett et al. in press), there is no evidence of a similar decline in kittiwake numbers in Murman. At Kharlov, the only colony where there has been regular monitoring since the 1960s (Krasnov \& Barrett 1995), numbers have fluctuated between 16000 and 28000 pairs, but with no evidence of a population trend between 1980 and 1999 (Fig. 2). Thus, with a recent total figure of ca. 140000 pairs, the former figure of 66900 pairs for the whole of Murman was probably an underestimate. This is probably partly because the former figure was based on counts made in the early 1960s (Gerasimova 1962), and numbers are known to have increased at Kharlov (Fig. 2), Sør-Varanger and Hornøya (Krasnov \& Barrett 1995) since then, and hence probably also increased at other colonies in the region. In Varanger, numbers have dropped since the mid 1980s in both SørVaranger and at Hornøya, and the present population of 31 000-32 000 pairs is approximately half of that documented in the early 1980s (Barrett 2003; Barrett et al. in press).

At Kharlov, earlier studies showed that kittiwake clutch size was a good indicator of feeding conditions early in the breeding season. At this time capelin was the main prey, and when present in large numbers in March-May the mean clutch size (excluding empty nests) was $\geq 2.0$ eggs, but when capelin was absent the mean clutch size was $\leq 1.6$ eggs (Barrett \& Krasnov 1996). Data from this study show that kittiwake mean clutch sizes at Cape
Krutik and Dvorovaya Bay were only once greater than 1.6, whereas at Kharlov the mean clutch size reached 1.6 or more in two out of three seasons (1995 and 1998; Table 2). In all cases (except at Cape Krutik in 2000), the mean clutch sizes were lower than at Hornøya in the same years (Student's $t$-test, $p \leq 0.01$ in all cases). Furthermore, large-scale breeding failures among kittiwakes were registered at Cape Gorodetskiy in 2000 and 2002 when $42.1 \%$ and $50.5 \%$ of the nests, respectively, did not contain eggs, and at Kharlov ca. 30\% of the nests were empty in 1996 and 1998 (YVK, pers. obs.). Only once, in 2002 , in the eight years covered here did the number of empty nests on Hornøya make up $>25 \%$ (29\%) of the total nests counted (RTB, pers. obs). This suggests that feeding conditions have, in recent years, often been poor prior to egg laying for kittiwakes along much of the Murman coast. Despite this reduction in the initial breeding success, the Murman population does not seem to have declined, whereas the population in Varanger, where clutch sizes were higher, has seriously declined.

Anker-Nilssen et al. (2000) cite 10 common guillemot colonies, totalling 20 000-30000 pairs (or 32 000-48 000 individuals, assuming a conversion factor of 0.6 individuals/pair; Anker-Nilssen et al. 2000), on the Murman coast. Although based on single counts, and thus not taking into account the diurnal and seasonal fluctuations in numbers of birds on the breeding shelf, the surveys were made during the late incubation/hatching period when such fluctuations are at a minimum (Barrett 2001), such that we are confident that the results from the present surveys in Murman are within the correct order of magnitude. Using the same conversion factor we estimate the total breeding population of common guillemots in Murman to be 10 000-12 000 pairs, suggesting that the figure given by Anker-Nilssen et al. (2000) was optimistic. There are, however, several complications inherent in any comparison between the present numbers and earlier totals. Many of the early counts were made from the sea, and there is a suspicion that they were underestimates. Furthermore, there have been huge fluctuations in numbers of common guillemots breeding in the region, including an $85 \%$ decline (from ca. 8000 to 1200 individuals at Kharlov) in 1986/87 (Krasnov \& Barrett 1995; Krasnov et al. 1995) followed by a recovery (at Kharlov to near pre-collapse levels, 6000 individuals in 1999; Fig. 2). As a result, it is difficult to determine the scale of any changes in guillemot numbers in Murman, and only at Dvorovaya Bay is the difference between ca. 4000 pairs (= ca. 7000 individuals) counted in the 1960s (Gerasimova 1962) and the 1000 individuals in 2003-2005 (this study) large enough to be convincing of a real decline. Here, there is no evidence of the rapid recovery documented in the two colonies further west (Kharlov 
and Hornøya) where seabirds have been regularly monitored. At Cape Krutik Gerasimova (1962) counted 320 pairs of guillemots, whereas the present figure was a maximum of 100 pairs.

The present total population of 3000-4000 pairs of Brünnich's guillemots in Murman is similar to the 3000 pairs given in Anker-Nilssen et al. (2000), suggesting little change over recent years.

With the exception of the collapse in the guillemot breeding populations at Kharlov in 1986/87 (Krasnov \& Barrett 1995), it is difficult to relate population data in Murman to changes in the marine environment such as food availability. The large decline and lack of evident recovery of the common guillemot population at Dvoroyaya Bay may, however, be the result of poorer feeding conditions (YVK, pers. obs.), and is of concern.

\section{Acknowledgements}

This study was partly financed by the University of Tromsø, the Norwegian SEAPOP project (Anker-Nilssen et al. 2005) and the Norwegian National Monitoring programme for seabirds (Lorentsen 2006). We thank Yuri Goryaev and Aleksey Ezhov for their help during field work and Svein-Håkon Lorentsen and two referees for their comments on earlier drafts of the manuscript.

\section{References}

Anker-Nilssen T., Bakken V., Strøm H., Golovkin A., Bianki V. \& Tatarinkova I.P. (eds.) 2000. The status of marine birds breeding in the Barents Sea region. Norsk Polarinstitutt Rapportserie 113.

Anker-Nilssen T., Bustnes J.O., Erikstad K.E., Fauchald P., Lorentsen S.-H., Tveraa T., Strøm H. \& Barrett R.T. 2005. SEAPOP. Et nasjonalt sjøfuglprogram for styrket beslutningsstøtte $i$ marine områder. (SEAPOP. A national seabird programme for improved decision support in marine areas.) NINA Rapport 1.

Barrett R.T. 2001. Monitoring the Atlantic puffin Fratercula arctica, common guillemot Uria aalge and black-legged kittiwake Rissa tridactyla breeding populations on Hornøya, northeast Norway, 1980-2000. Fauna Norvegica 21, 1-10.

Barrett R.T. 2003. The rise and fall of cliff-breeding seabirds in Sør-Varanger, North Norway, 1970-2002. Fauna Norvegica 23, 35-41.

Barrett R.T. \& Krasnov Y.V. 1996. Recent responses to changes in stocks of prey species by seabirds breeding in the southern Barents Sea. ICES Journal of Marine Science 53, 713-722.
Barrett R.T., Lorentsen S.-H. \& Anker-Nilssen T. in press. The status of breeding seabirds in mainland Norway. Atlantic Seabirds.

Durant J.M., Anker-Nilssen T. \& Stenseth N.C. 2003. Trophic interactions under climate fluctuations: the Atlantic puffin as an example. Proceedings of the Royal Society, London B 270, 1461-1466.

Durant J.M., Anker-Nilssen T. \& Stenseth N.C. 2006. Ocean climate prior to breeding affects the duration of the nesting period of the Atlantic puffin. Biology Letters 2, 628-631.

Frederiksen M., Edwards M., Richardson A.J., Halliday N.C. \& Wanless S. 2006. From plankton to top predators: bottom-up control of a marine food web across four trophic levels. Journal of Animal Ecology 75, 1259-1268.

Furness R.W. \& Barrett R.T. 1985. The food requirements and ecological relationships of a seabird community in north Norway. Ornis Scandinavica 16, 305-313.

Gerasimova T.D. 1962. Sostoyanie ptich'ikh bazarov Murmanskogo poberezh'ya. (The status of the seashore bird colonies on the Murmansk shore.) Ornithology (Moscow) 4 , $11-14$.

Golovkin, A.N. 1984. Seabirds nesting in the USSR: the status and protection of populations. ICPB Technical Publication 2, 473-486.

Iversen S.A., Fossum P., Gjøsæter H., Skogen M. \& Toresen R. (eds.) 2006. Havets Ressurser og Miljø 2006. (The ocean's resources and environment.) Fisken og Havet, særnummer 1-2006.

Krasnov J.V. \& Barrett R.T. 1995. Large-scale interactions among seabirds, their prey and humans in the southern Barents Sea. In H.R. Skjoldal et al. (eds.): Ecology of fjords and coastal waters. Pp. 443-456 Amsterdam: Elsevier Science.

Krasnov Y.V., Matishov G.G., Galaktionov K.V. \& Savinova T.N. 1995. Morskiye kolonialniye ptitsi Murmana. (The colonial seabirds of Murman.) St. Petersburg: Nauka Publishers.

Lorentsen S.-H. 2006. Det nasjonale overvåkningsprogrammet for sjøfugl. Resultater til og med hekkesesongen 2006. (The national monitoring programme for seabirds. Results up to and including the 2006 breeding season.) NINA Rapport 203.

Quillfeldt C.H. \& Dommasnes A. (eds.) 2005a. Forslag til indikatorer og miljøkvalitetsmål for Barentshavet. Rapport fra et delprosjekt under forvaltningsplanen for Barentshavet. (Proposals for indicators and environmental quality objectives for the Barents Sea. Report from a sub-project under the management plan for the Barents Sea.) Accessed on the internet at http://barentshavet.imr.no on 30 April 2007.

Quillfeldt C.H. \& Dommasnes A. (eds) 2005b. The Scientific Basis for Environmental Quality Objectives (EcoQOs) for the Barents Sea ecosystem. Working group report on Seabirds and Marine Mammals. Accessed on the internet at http://barentshavet.imr.no on 30 April 2007. 